\title{
Remote sensing to monitor cover crop adoption in southeastern Pennsylvania
}

\author{
W.D. Hively, S. Duiker, G. McCarty, and K. Prabhakara
}

\begin{abstract}
In the Chesapeake Bay Watershed, winter cereal cover crops are often planted in rotation with summer crops to reduce the loss of nutrients and sediment from agricultural systems. Cover crops can also improve soil health, control weeds and pests, supplement forage needs, and support resilient cropping systems. In southeastern Pennsylvania, cover crops can be successfully established following corn (Zea mays L.) silage harvest and are strongly promoted for use in this niche. They are also planted following corn grain, soybean (Glycine max L.), and vegetable harvest. In Pennsylvania, the use of winter cover crops for agricultural conservation has been supported through a combination of outreach, regulation, and incentives. On-farm implementation is thought to be increasing, but the actual extent of cover crops is not well quantified. Satellite imagery can be used to map green winter cover crop vegetation on agricultural fields and, when integrated with additional remote sensing data products, can be used to evaluate wintertime vegetative groundcover following specific summer crops. This study used Landsat and SPOT (System Probatoire d' Observation de la Terre) satellite imagery, in combination with the USDA National Agricultural Statistics Service Cropland Data Layer, to evaluate the extent and amount of green wintertime vegetation on agricultural fields in four Pennsylvania counties (Berks, Lebanon, Lancaster, and York) from 2010 to 2013. In December of 2010, a windshield survey was conducted to collect baseline data on winter cover crop implementation, with particular focus on identifying corn harvested for silage (expected earlier harvest date and lower levels of crop residue), versus for grain (expected later harvest date and higher levels of crop residue). Satellite spectral indices were successfully used to detect both the amount of green vegetative groundcover and the amount of crop residue on the surveyed fields. Analysis of wintertime satellite imagery showed consistent increases in vegetative groundcover over the four-year study period and determined that trends did not result from annual weather variability, indicating that farmers are increasing adoption of practices such as cover cropping that promote wintertime vegetation. Between 2010 and 2013 , the occurrence of wintertime vegetation on agricultural fields increased from $36 \%$ to $67 \%$ of corn fields in Berks County, from 53\% to 75\% in Lancaster County, from $42 \%$ to $65 \%$ in Lebanon County, and from $26 \%$ to $52 \%$ in York County. Apparently, efforts to promote cover crop use in the Chesapeake Bay Watershed have coincided with a rapid increase in the occurrence of wintertime vegetation following corn harvest in southeastern Pennsylvania. However, despite these increases, between $25 \%$ and $48 \%$ of corn fields remained without substantial green vegetation over the wintertime, indicating further opportunity for cover crop adoption.
\end{abstract}

Key words: cover crop-Landsat-nitrogen-normalized difference vegetation indexremote sensing-satellite

\begin{abstract}
Winter cover crops are planted at the end of the summer crop growing season and provide living groundcover throughout the winter season. This vegetation helps to reduce soil erosion and phosphorus $(\mathrm{P})$ loss and also accumulates residual soil nitrogen $(\mathrm{N})$ into its biomass, reducing the risk
\end{abstract}

as improving soil health by alleviating soil compaction, increasing soil organic matter and aggregate stability, providing surface mulch, conserving moisture, and controlling weeds and pests (Dabney et al. 2001; Magdoff and van Es 2009; SANET 2007; Sarrantonio and Gallandt 2003; Teasdale et. al. 2007). In the Chesapeake Bay Watershed, particular focus is placed on the use of winter cover crops as a conservation practice to control nutrient and sediment loss from farmland (CBP 2014; MDA 2014; Staver and Brinsfield 1998). The agricultural region located in southeastern Pennsylvania, United States, contributes a large portion of nutrient and sediment loads to the Chesapeake Bay via the Susquehanna River and is an important area for implementation of agricultural conservation practices (Zhang et al. 2013).

To provide substantial wintertime conservation benefits, cover crops should be established early enough and with adequate planting success to provide sufficient fall growth (groundcover and nutrient uptake) to have an impact on nutrient and sediment losses. Factors affecting cover crop performance include species choice, planting method, planting date, available soil $\mathrm{N}$, soil type, landscape position, and climatic growing conditions (precipitation, temperature, and sunlight) (Duiker 2014; Hively et al. 2009b).

Southeastern Pennsylvania is a favorable region for winter cover crops due to a comparatively long fall growing season. The most common winter cover crops that are used following corn (Zea mays L.) or soybean (Glycine max L.) harvest are cereal grains, including wheat (Triticum aestivum L.), rye (Secale cereale L.), and barley (Hordeum vulgare L.). In addition to winter cereals, farmers also use a variety of legumes and brassicas as cover crops, either separately or in mixtures, and there is considerable innovation in cover crop equipment and management strategies.

W. Dean Hively is a research physical scientist with the US Geological Survey, Eastern Geographic Science Center, and is stationed in Beltsville, Maryland. Sjoerd Duiker is associate professor of soil management and applied soil physics at Penn State University, University Park, Pennsylvania. Gregory McCarty is a soil scientist with the USDA Agricultural Research Service, Hydrology and Remote Sensing Laboratory, Beltsville, Maryland. Kusuma Prabhakara is a PhD candidate in the University of Maryland, Department of Geographical Sciences, College Park, Maryland. 
Seeding is achieved using no-till drills, or by broadcasting the seed on the soil surface and incorporating it into the soil with shallow tillage. Aerial seeding into standing crops is also practiced, but with mixed results due to the inconsistency of seed-to-soil contact and rainfall after seeding. New local techniques used for cover crop establishment include interseeding into young standing corn using a specialized interseeder that also side-dresses fertilizer and applies herbicide, or interseeding in chest-high corn with a highboy applicator that drops cover crop seeds between standing rows of corn. Frost seeding red clover (Trifolium pratense L.) into standing wheat or barley in February or March (Hesterman et al. 1992) is a method used to establish a leguminous cover crop that will occupy the field after small grain harvest. Relatively new cover crops such as forage radish (Raphanus sativus L.), annual ryegrass (Lolium multiflorum Lam.), crimson clover (Trifolium incarnatum L.), and hairy vetch (Vicia villosa Roth) have to be established before mid-September in this region to enhance growth and winter survival, which can be accomplished after small grain, vegetable, or corn silage harvest. Oats (Avena sativa L.) are a winter-killed cover crop that can be established after corn silage. There is much on-farm and on-station experimentation by farmers and researchers to develop successful cover crop mixtures and rotations.

Planting cover crops following corn silage harvest is considered an important niche due to the early harvest date of the greenchopped corn silage, which occurs several weeks before corn grain harvest. The early harvest provides a window of opportunity for cover crop establishment and growth under warm soil conditions, prior to the onset of winter. Planting of winter cover crops following silage harvest is an important conservation target, because harvest of the entire corn plant leads to low levels of crop residue and high potential for soil erosion. Silage crops also tend to be associated with dairy farms, and these fields often receive manure applications in the fall, with associated risk of wintertime nutrient losses.

Factors Affecting Cover Crop Adoption Trends in Pennsylvania. Pennsylvania farmers plant cover crops for a variety of reasons including soil health benefits, weed and pest control, and forage supply, as well as control of soil erosion and nutrient loss. Many factors influence farmer adoption of cover crops, including incentives (the carrots) such as costshare programs available through the Soil Conservation Districts and USDA programs, regulations (the sticks) such as groundcover requirements on highly erodible lands, and voluntary factors (without carrot or stick) such as on-farm forage harvest, grazing, and soil improvement, as well as educational programs to improve soil health, crop productivity, and nutrient efficiency.

Carrots. Cost-share funds for cover crops were available to Pennsylvania farmers through the USDA Natural Resources Conservation Service (NRCS) as well as various county programs. From 2010 to 2013, an accumulated implementation of 1,032 ha $(3,550 \mathrm{ac})$ of USDA-supported cover crops (NRCS Practice 340) was recorded by the Soil Conservation Districts in Berks, Lancaster, Lebanon, and York counties, Pennsylvania (Hively et al. 2013). These incentive programs encourage the planting of cover crops by offsetting the on-farm costs of cover crop management (seed and tractor time).

Sticks. In the rolling landscape of southeastern Pennsylvania, winter cover crops are often used by farmers to meet soil conservation requirements on highly erodible land, often in combination with other soil conserving practices such as reduced tillage, residue management, terraces, and contour strip cropping. New manure management regulations came into effect in Pennsylvania on October 29, 2011 (DEP 2011). These regulations included restrictions to winter spreading of manure between December 15 and February 28, or when the ground is frozen more than $10 \mathrm{~cm}$ (4 in), or when the ground is snow covered. No winter surface application of manure is currently allowed on fields with less than $25 \%$ groundcover provided by either crop residue or a cover crop. This restriction essentially requires the use of cover crops after corn silage harvest if farmers want to apply manure in the winter, due to low levels of crop residue cover following corn silage harvest. Because farms must be in compliance with regulations to participate in farm insurance and commodity price support programs, the combination of federal and state regulations that promote soil conservation and manure nutrient management has likely been an important factor promoting the adoption of winter cover crops in Pennsylvania.

Without Carrot or Stick. Voluntary adoption of cover crops stems from tradition (stewardship ethic), innovation (integration of cover crops into crop rotations to promote soil health, nutrient cycling, and agroecosystem benefits), and integration with cropping systems (for example, ryelage cover crops are often grown on dairy farms and chopped for feed in the springtime, and a variety of cover crops are commonly used to provide weed, nutrient, and pest control in organic vegetable crops) (SANET 2007). From 2010 to 2013, a cover crop extension project titled "Without Carrot or Stick" was sponsored by a USDA Conservation Innovation Grant (NRCS agreement \#69-3A75-10-160). The project aimed to stimulate the planting of cover crops after corn silage harvest, with an objective of reducing nutrient and sediment loss to the Chesapeake Bay. The project used on-farm research to investigate and demonstrate new cover crop species and mixtures, along with a comprehensive outreach program associated with the Penn State Cooperative Extension Service. This approach was proposed to be more effective and less costly than "stick" approaches of environmental laws and "carrot" approaches of subsidies. The project used a variety of outreach approaches to stimulate cover crop use after corn silage harvest, while also building partnerships between the cooperative extension, farmers, and agribusiness. The outreach methods included on-farm research and demonstrations, field days including host farmer testimonials, winter farm meeting presentations, farm journal articles and interviews, and advertisements to stimulate dairy farmers to use cover crops after corn silage. Approximately 10 small-to-medium scale dairy farms hosted research and demonstration plots each year from 2010 to 2013. The farm locations varied from year to year to increase geographic impact. The use of remote sensing to monitor cover crop adoption was funded as part of this larger project.

Remote Sensing of Wintertime Vegetation. Satellite imagery can be used to characterize the properties of vegetation on Earth's surface. The information contained within each pixel of a multiband satellite imagery can be correlated to measurements of plant leaf area index, biomass, and percentage vegetative groundcover using various band ratio indices, most of which focus on the ratio of increased plant reflectance in the near infrared or green wavelengths to reduced reflectance in the red wavelengths that results from the chlorophyll adsorption 
feature (Barnnaria et al. 1995; Moges et al. 2004; Thenkabail et al. 2000). For the early growth stages of winter cover crops, plant reflectance is mixed with the reflectance of exposed soils and crop residues, reducing the vegetation signal. Previous studies have used remotely sensed spectral indices, in combination with site-specific agronomic data, to measure the extent and biomass of winter cover crop vegetative groundcover in Maryland (Hively et al. 2009a, 2009b; Hunt et al. 2011; Prabhakara et al. 2015).

Remotely sensed spectral indices have also been used to measure the amount of crop residue on agricultural lands, with success achieved by using indices that span the cellulose shortwave infrared adsorption feature found near 2,200 $\mathrm{nm}$, or by detecting differences in brightness between the soil and the crop residue (Daughtry 2001; Daughtry et al. 2006; Gausman et al. 1977; Gelder et. al. 2009; Serbin et al. 2009a, 2009b). These indices are most effective on fields with minimal green vegetation (Gelder et al. 2009).

The US government provides Landsat satellite imagery at no cost to the public (USGS 2014a; Woodcock 2008) through a partnership between the US Geological Survey (USGS), and the National Aeronautics and Space Administration. The USGS also provides access to additional multispectral satellite sensors such as SPOT (System Probatoire d' Observation de la Terre). These satellite data sources provide frequent images of the land's surface, but are limited by the spatial and spectral resolution of the imagery, the occurrence of clouds, and the overpass times of the satellites.

Since 2008, the USDA National Agricultural Statistical Service (USDA NASS) has produced annual maps of summer crop type for the United States at $30 \mathrm{~m}$ (98 ft) resolution based upon identification of crop phenological patterns in a time series of satellite imagery (Boryan et al. 2011). This Cropland Data Layer (CDL) provides the ability to distinguish crop type on fields throughout the agricultural landscape. When combined with satellite vegetation analysis, this information allows measurement of wintertime vegetative groundcover on agricultural fields, by previous crop type.

Objectives. The goal of this study was to assess the extent of winter cover crops following the harvest of summer crops, from 2010 to 2013, in southeastern Pennsylvania. Windshield survey data were used to observe differences in cover cropping following harvest of summer crops, including differentiation between corn harvested for silage (COS) versus corn harvested for grain (COG), and to calibrate a satellite remote sensing analysis that assessed multiyear trends in the occurrence of wintertime green vegetative groundcover on agricultural fields. A secondary objective was to investigate the utility of satellite multispectral indices for the identification of COG versus COS based upon detection of crop residue.

\section{Materials and Methods}

Study Location. From 2010 to 2013, the "without carrot or stick" cover crop program engaged with farmers and farm service providers throughout central and southeastern Pennsylvania to promote the use of cover crops following corn silage harvest. In five counties (figure 1), windshield survey data were collected to evaluate cover crop usage following various crops, with an emphasis on corn silage harvest.

Windshield Survey. In December of 2010, five Pennsylvania counties (Berks, Centre, Lancaster, Lebanon, and York) were surveyed by collaborating cooperative extension agents (figure 1). The agents drove specified routes through farmlands and collected data on 1,573 agricultural fields, recording the estimated amount of green vegetative groundcover, previous crop, tillage, and cover crop planting method for each field based on visual observations made from the road (figure 2). Vegetative groundcover was categorized into four classes $(0=$ minimal, $1=$ low, 2 = medium, and $3=$ high) that corresponded with approximately $<10 \%, 10 \%$ to $30 \%, 30 \%$ to $60 \%$, and $>60 \%$ green vegetative groundcover. Photographs of vegetation levels associated with each of the vegetative groundcover classes are provided in figure $2 \mathrm{c}$.

Field boundaries for each windshield survey location were digitized in ArcGIS 9.3, using 2010 National Agricultural Imagery Program imagery (USDA 2014) as a reference. To obtain spectral reflectance data for each field, the field boundaries were buffered inward by $30 \mathrm{~m}(98 \mathrm{ft}$ ) to remove field edge effects (mixed pixels), and average values of satellite spectral indices for each field were calculated. Differences among vegetative groundcover classes from the windshield survey were determined using box plot analysis in the $\mathrm{R}$ statistical package. The survey data were used to validate the remote sensing analysis and to gain insight into the distribution of wintertime vegetative groundcover following various summer crops, with particular emphasis on fields with COG versus fields with COS.

Imagery and Climate Data Sources. The best clear wintertime satellite images for each county were identified from either the Landsat data archive or from SPOT imagery obtained through the USGS SPOT Data Buy. One late winter image (late February to early April) was chosen for each year to support groundcover analysis, and an early winter image (November 14) was chosen for 2010 to correspond with the windshield survey data collection, described below.

The Landsat images were downloaded as top of atmosphere reflectance, including cloud masking, from the USGS Earth Science Processing Architecture site maintained by the USGS Earth Resources Observation and Science Center (USGS 2014b). The SPOT imagery was downloaded from the USGS Earth Explorer website (USGS 2014a) as a Level 1 Gst product and was converted to top of atmosphere reflectance and smoothed to $30 \mathrm{~m}$ (98 ft) resolution using ENVI 4.8 software (Exelis Visual Information Solutions, Boulder, Colorado).

Top of atmosphere reflectance for each image was used to calculate the normalized difference vegetation index (NDVI; Gelder et al. 2009):

$\mathrm{NDVI}=(\mathrm{NIR}-\mathrm{R}) \div(\mathrm{NIR}+\mathrm{R})=(\mathrm{TM} 4$
$-\mathrm{TM} 3) \div(\mathrm{TM} 4+\mathrm{TM} 3)$,

and the normalized difference residue index (NDRI; Gelder et al. 2009) and normalized difference tillage index (NDTI; Gelder et al. 2009) were calculated for the November 14 , 2010, Landsat 5 imagery as follows:

$\mathrm{NDRI}=(\mathrm{R}-\mathrm{SWIR}) \div(\mathrm{R}+\mathrm{SWIR})=$ $(\mathrm{TM} 3-\mathrm{TM} 7) \div(\mathrm{TM} 3+\mathrm{TM} 7)$, and

NDTI $=($ SWIR $1-$ SWIR 2$) \div($ SWIR 1 + SWIR2) $=($ TM5 - TM7 $) \div($ TM5 + TM7),

using the Landsat Thematic Mapper (TM) spectral bands: TM3 spanning the red (R) wavelengths (630 to $690 \mathrm{~nm}$ ), TM4 spanning the near infrared (NIR) wavelengths (770 to $900 \mathrm{~nm}$ ), TM5 spanning the shortwave infrared (SWIR1) wavelengths $(1,550$ 


\section{Figure 1}

Pennsylvania study areas including satellite imagery footprints and windshield survey locations.

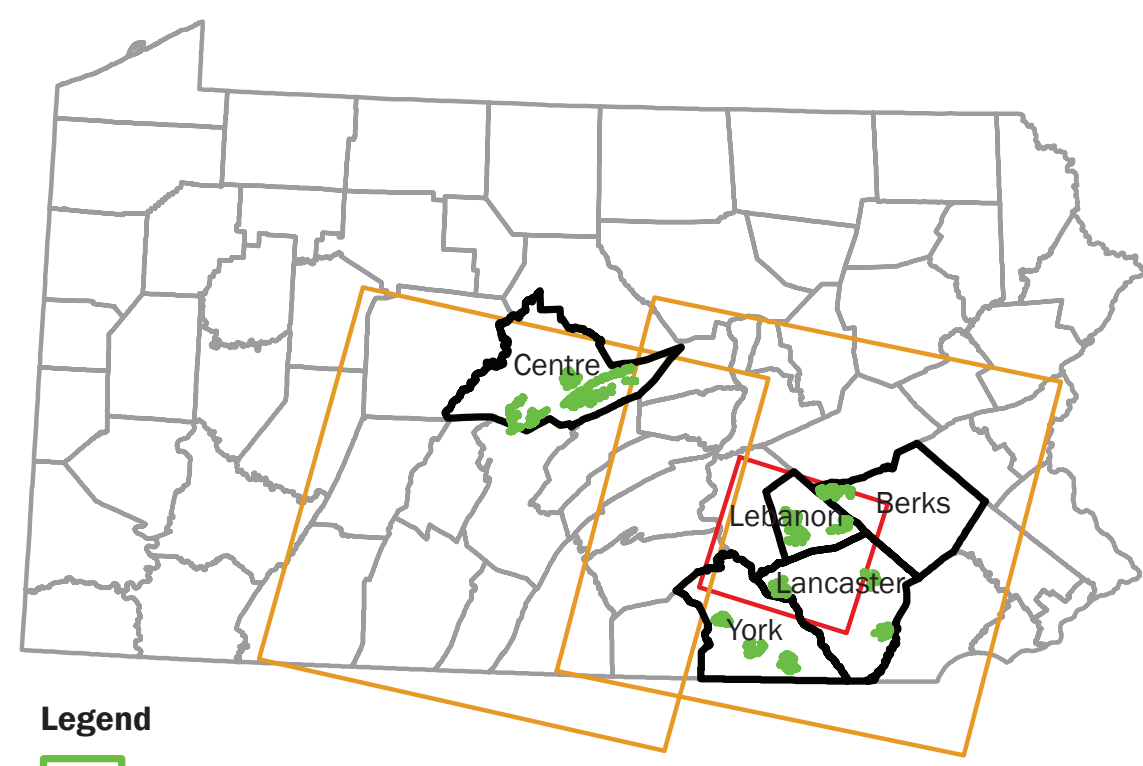

December 2010 windshield survey

Pennsylvania county boundaries

Windshield survey focus counties

Landsat satellite footprints

SPOT satellite footprint

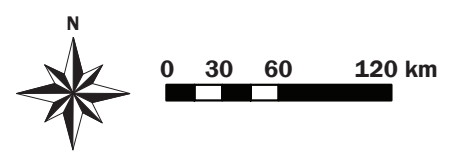

\section{Results and Discussion}

Windshield Survey-Vegetative Groundcover. The best available Landsat image acquired close to the time of the windshield survey (early December of 2010) was a November 14, 2010, Landsat 5 image (LT50160322010318EDC00) covering Centre County, Pennsylvania. In Centre County, of the 685 fields included in the December of 2010 windshield survey, 458 had an identified previous crop in the survey data and were large enough that satellite reflectance index values could be extracted after the field boundaries were buffered inward by $30 \mathrm{~m}$ (98 ft) to reduce field edge effects (table 1). Of the 227 excluded fields, 96 were narrow contour-strip fields with a maximum width $<90 \mathrm{~m}(<295 \mathrm{ft})$, and so were not suitable for remote sensing analysis using $30 \mathrm{~m}$ pixel resolution, and 131 fields did not have a data for vegetative groundcover or previous crop recorded.

For the 458 surveyed fields, the mean NDVI values derived from the November 14 satellite image increased regularly with increasing categories of surveyed vegetative groundcover (table 1 and figure 3a). The observed ranges of NDVI for each of the four surveyed vegetative groundcover categories (minimal, low, medium, and high) resembled NDVI threshold values derived from top of atmosphere satellite reflectance for sampled cover crop fields in Maryland and are consistent with the documented use of NDVI to monitor wintertime vegetation on cover cropped fields on the Eastern Shore of Maryland (Hively et al. 2009a, 2009b). The midpoints between the average NDVI values for vegetative groundcover categories following corn (table 1) were used to establish threshold values (minimal $<0.29<$ low $<0.40<$ medium $<0.53<$ high) for satellite analysis of vegetative ground cover, as described below.

Within the November 14 satellite image, corn grain and soybean fields exhibited the lowest levels of green vegetative groundcover (table 1, figure 3b), which was consistent with their relatively late harvest dates and the limited time available for cover crop planting and growth following their harvest. Corn grain harvest was strongly associated with minimal wintertime vegetation (only $1.5 \%$ of surveyed fields had more than minimal vegetative cover). Corn silage fields, on the other hand, exhibited significantly higher levels of wintertime vegetation

ing on salculated startto evaluate the timing of each satellite image relative to cover crop growing conditions.

Groundcover Analysis. To complement the use of satellite imagery, annual $30 \mathrm{~m}$ (98 ft) raster maps of the CDL were obtained from USDA NASS (Boryan et al. 2011). This CDL dataset, which is derived the windshield survey. This approach mapping of winter ground outcomes following each predominant type of summer row crop identified in the CDL (corn, soybean, cereals, and hay). This analysis was applied to four focus counties (Berks, Lancaster, Lebanon, and York) for four successive years (2010 to 2013). 


\section{Figure 2}

Example windshield survey field boundaries (purple lines) and $30 \mathrm{~m}$ buffer boundaries (white lines), including survey scorings for (a) vegetative groundcover ( $0=$ minimal, $1=$ low, $2=$ medium, and $3=$ high) and (b) previous summer crop type (corn silage [COS], corn grain [COG], soy, and hay), with background Landsat 5 satellite imagery (false color near infrared display) acquired on November 14, 2010. Brighter red colors indicate more vegetation. (c) Example photographs representing vegetation levels associated with each winter cover crop vegetative groundcover class $(\mathrm{minimal}=$ no cover crop growth, up to $10 \%$ light weed cover; low = cover crop in early non-tillered growth stages, $10 \%$ to $25 \%$ vegetative groundcover; medium $=$ good cover crop growth, $\mathbf{2} 25 \%$ vegetative groundcover; and high = lush cover crop growth, $>60 \%$ vegetative groundcover).

(a)

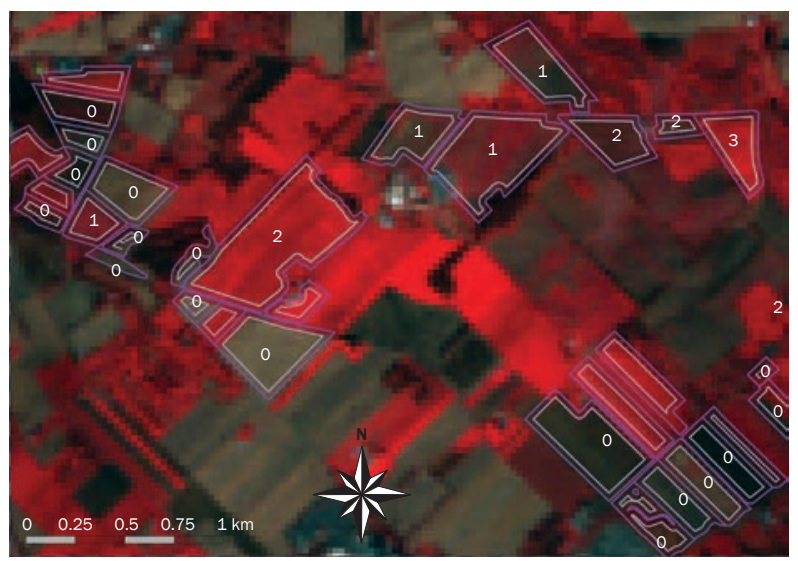

(b)

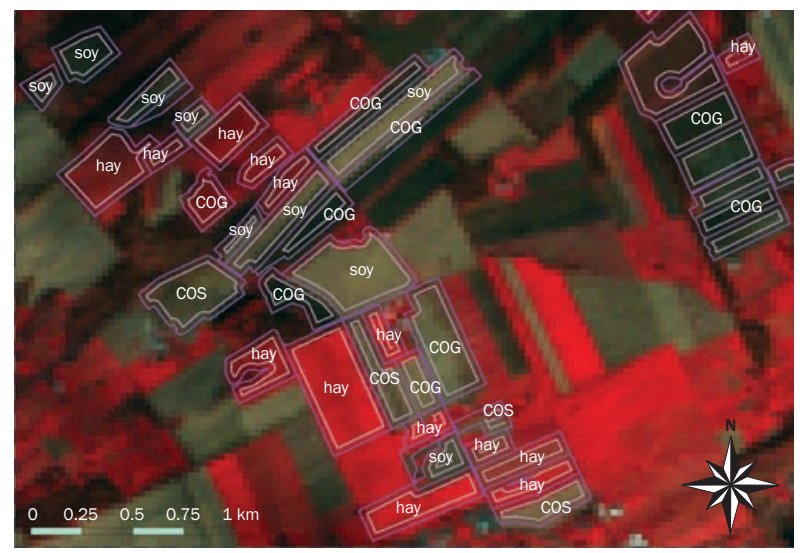

$2=$ Medium

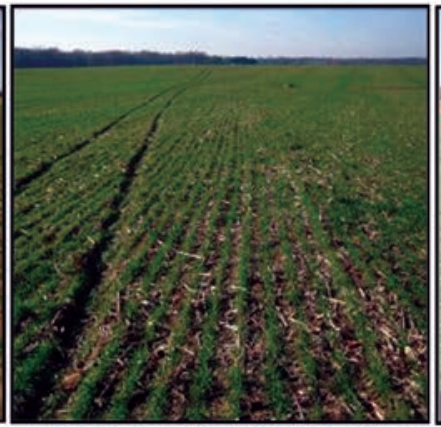

$3=$ High

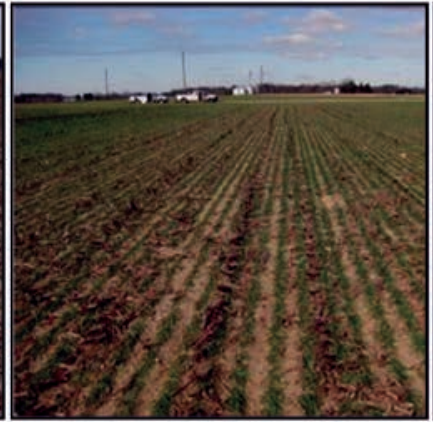

(c)

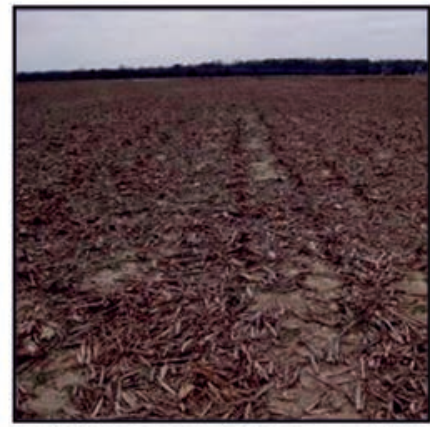

$1=$ Low

(45.3\% exhibiting nonminimal vegetative cover), as might be expected from the longer available cover crop growing season following the comparatively early harvest of corn silage crops. Fields previously cropped to cereal grains also exhibited substantial levels of winter groundcover $(38.5 \%$ nonminimal vegetative cover), likely associated with clover cover crops, postharvest sprouting of cereal seeds, or growth of weeds, while hay fields exhibited the highest levels of vegetation (62.5\% nonminimal vegetative cover) as might be expected from their perennial nature. When all corn fields were combined and harvest method was not distinguished, as would be the case when using the CDL crop type designation for remote sensing analysis, an overall $22.6 \%$ of corn fields exhibited some growth of vegetation (scored as low, medium, or high vegetative groundcover). However, the windshield survey data (table
1) revealed that the vast majority of this vegetative groundcover occurred following corn silage harvest. This finding is in agreement with local knowledge that cover crops are predominantly planted following silage harvest, rather than grain harvest, due to the lateness of corn grain harvest relative to the fall growing season.

In addition to Centre County, windshield survey data were also collected in Berks, Lebanon, Lancaster, and York counties in December of 2010. The results, which were not used for satellite imagery calibration due to lack of properly timed imagery, are presented in table 2. In the four counties, nonminimal amounts of vegetative groundcover were observed on the majority of fields harvested for corn silage (68\% to $82 \%$ ) but not on fields harvested for corn grain ( $5 \%$ to $42 \%$ ), supporting the supposition that the earlier harvest dates of corn silage, com- bined with various incentives, regulations, and extension programs, has led to frequent use of cover crops following silage harvest.

Windshield Survey-Crop Residue. To distinguish between COG and COS using remote sensing, it was postulated that the NDRI or the NDTI could be used to distinguish fields with high levels of crop residue (likely to be COG) from fields with low levels of crop residue (likely to be COS). This hypothesis was evaluated on the set of fields that were identified as corn crops by the windshield survey. Because the presence of green vegetation interferes with remote sensing of crop residue (Gelder et al. 2009; Daughtry et al. 2006), analysis was limited to the 311 fields that displayed mean NDVI $<0.25$ in the November 14 satellite image. Because the NDRI and NDTI analyses were limited to fields with minimal vegetation, the biophysical components of each pixel 


\section{Table 1}

Windshield survey data for Centre County, Pennsylvania, in December of 2010, including number of fields ( $n$ ) and average normalized difference vegetation index (NDVI) of fields falling within each combination of previous crop and vegetative groundcover category. Crop type and vegetative groundcover categories were derived from windshield survey field observations. The average NDVI was calculated for each surveyed field using November 14, 2014, Landsat 5 imagery, and the resulting values were subsequently averaged within previous crop and vegetative groundcover category.

\begin{tabular}{|c|c|c|c|c|c|c|c|c|c|c|c|}
\hline \multirow[b]{3}{*}{ Previous crop } & \multirow{2}{*}{\multicolumn{2}{|c|}{ Total }} & \multicolumn{8}{|c|}{ Surveyed vegetative groundcover category } & \multirow{3}{*}{$\begin{array}{l}\text { Percent } \\
\text { non-minimal (\%) }\end{array}$} \\
\hline & & & \multicolumn{2}{|c|}{$\underline{\text { Minimal }}$} & \multicolumn{2}{|c|}{ Low } & \multicolumn{2}{|c|}{ Medium } & \multicolumn{2}{|c|}{ High } & \\
\hline & $\bar{n}$ & Area (ha) & $\bar{n}$ & NDVI & $\bar{n}$ & NDVI & $\bar{n}$ & NDVI & $\bar{n}$ & NDVI & \\
\hline All field crops* & 422 & 1,268 & 331 & 0.232 & 49 & 0.315 & 30 & 0.449 & 12 & 0.601 & 21.6 \\
\hline All corn† & 262 & 763 & 203 & 0.239 & 28 & 0.347 & 23 & 0.446 & 8 & $0.618 \neq$ & 22.5 \\
\hline Corn grain & 136 & 417 & 134 & 0.232 & 1 & 0.303 & 1 & 0.481 & 0 & na & 1.5 \\
\hline Corn silage & 126 & 347 & 69 & 0.252 & 27 & 0.349 & 22 & 0.444 & 8 & 0.618 & 45.2 \\
\hline Hay & 32 & 59 & 12 & 0.381 & 9 & 0.529 & 2 & 0.259 & 9 & 0.463 & 62.5 \\
\hline Overall & 454 & 1,328 & 343 & 0.237 & 58 & 0.348 & 32 & 0.438 & 21 & 0.541 & 24.4 \\
\hline
\end{tabular}

*Sum of values for corn harvested for grain, corn harvested for silage, soy, and cereal.

†Sum of values for corn harvested for grain and corn harvested for silage.

$\ddagger$ The midpoints between underlined NDVI values were used as thresholds for satellite analysis of vegetative groundcover.

\section{Figure 3}

Box plots of normalized difference vegetation index (NDVI) values associated with windshield survey fields (one averaged NDVI value per field [dark line $=$ median, black point $=$ average, white box $=25 \%$ quartiles, and whiskers $=$ range]). (a) NDVI values within each vegetative groundcover class (minimal, low, medium, high =0, 1, 2, and 3, respectively) for corn fields (see figure $2 \mathrm{c}$ for definitions of vegetative groundcover categories). (b) NDVI values by crop type, including corn harvested for grain (COG) and corn harvested for silage (COS).

(a)

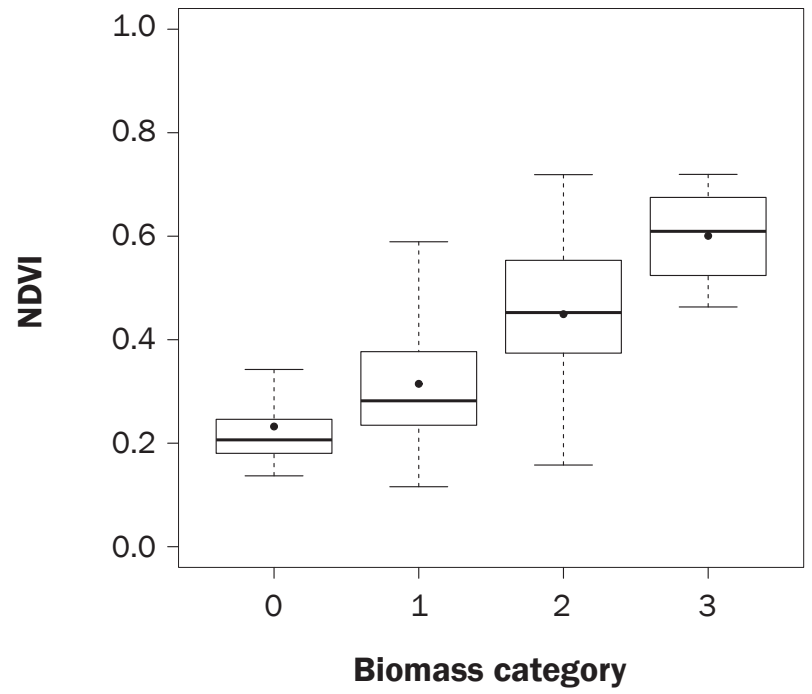

(b)

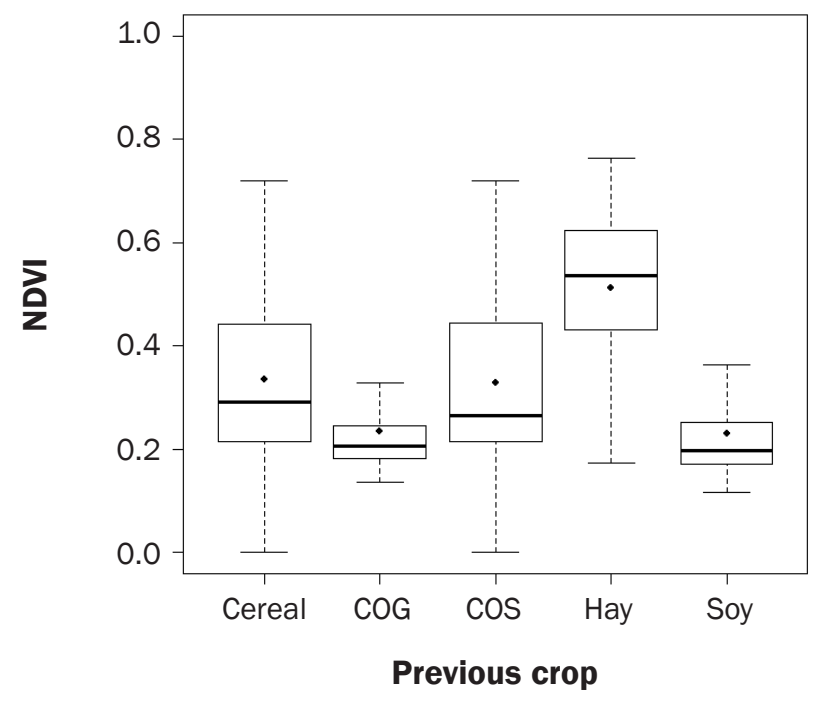

were limited to varying ratios of crop residue and bare soil, without the masking effect of vegetation.

Results (figure 4a) showed that the NDTI successfully distinguished fields with COG from fields with COS, with increased NDTI values associated with COG that were likely attributable to the greater amount of crop residue retained following grain harvest in contrast with minimal retention of crop residue following silage harvest. The NDRI was also higher for COG, although the distinction from COS was not as clear (figure 4b). The observed differences could possibly be exploited on an operational basis to distinguish between COG and COS, as long as imagery was acquired after corn harvest and prior to fall tillage, and analysis was limited to fields with minimal vegetation.

Previous research (Gausman et al. 1977; Aase and Tanaka 1991; Nagler et al. 2000; Daughtry 2001) has shown that soil reflec- tance and residue reflectance do not differ greatly in the visible and near infrared wavelengths (400 to $1,100 \mathrm{~nm}$ ) except in terms of brightness, and that there is a cellulose adsorption feature around 2,240 $\mathrm{nm}$. The brightness of soils and of crop residue depends upon soil type, residue type, moisture content of soil and residue (wetter = darker), and the stage of residue decomposition (Serbin et al. 2009a; Daughtry et al. 2010). The greatest contrast between soils 
Table 2

Windshield survey results for four Pennsylvania counties, December of 2010.

\begin{tabular}{|c|c|c|c|c|c|c|}
\hline \multirow[b]{2}{*}{ Summer crop } & \multicolumn{5}{|c|}{ Vegetative biomass category } & \multirow{2}{*}{$\begin{array}{l}\text { Percent } \\
\text { vegetated } \dagger\end{array}$} \\
\hline & $n *$ & Minimal & Low & Medium & High & \\
\hline \multicolumn{7}{|l|}{ Berks County } \\
\hline All corn $\ddagger$ & 120 & 56 & 8 & 12 & 44 & 53 \\
\hline Corn grain & 33 & 28 & 3 & 1 & 1 & 15 \\
\hline Corn silage & 87 & 28 & 5 & 11 & 43 & 68 \\
\hline Hay & 136 & 0 & 6 & 16 & 114 & 100 \\
\hline Soy & 60 & 35 & 16 & 8 & 1 & 42 \\
\hline \multicolumn{7}{|c|}{ Lancaster County } \\
\hline All corn & 65 & 24 & 19 & 10 & 12 & 63 \\
\hline Corn grain & 31 & 18 & 12 & 1 & 0 & 42 \\
\hline Corn silage & 34 & 6 & 7 & 9 & 12 & 82 \\
\hline Hay & 17 & 0 & 0 & 8 & 9 & 100 \\
\hline Soy & 17 & 10 & 5 & 2 & 0 & 41 \\
\hline \multicolumn{7}{|l|}{ Lebanon County } \\
\hline All corn & 96 & 34 & 3 & 26 & 33 & 65 \\
\hline Corn grain & 22 & 21 & 0 & 1 & 0 & 5 \\
\hline Corn silage & 74 & 13 & 3 & 25 & 33 & 82 \\
\hline Hay & 0 & 0 & 0 & 0 & 0 & na \\
\hline Soy & 48 & 35 & 3 & 6 & 4 & 27 \\
\hline \multicolumn{7}{|l|}{ York County } \\
\hline All corn & 132 & 109 & 15 & 5 & 3 & 17 \\
\hline Corn grain & 119 & 106 & 12 & 1 & 0 & 11 \\
\hline Corn silage & 13 & 3 & 3 & 4 & 3 & 77 \\
\hline Hay & 93 & 1 & 3 & 8 & 81 & 99 \\
\hline Soy & 104 & 79 & 24 & 1 & 0 & 24 \\
\hline
\end{tabular}

*Number of fields surveyed.

†Proportion of fields that scored as nonminimal vegetative biomass.

$\ddagger$ Sum of corn grain and corn silage.

and residues is likely to be obtained shortly after fall harvest and prior to any fall tillage, allowing a brief window of opportunity for data collection that could be used to identify COS versus COG, after which wintertime vegetation analysis could be applied to these crop types in the landscape.

Imagery and Climate Data Supporting Vegetative Groundcover Analysis. Four counties that had participated in the "without carrot or stick" program (Berks, Lancaster, Lebanon, and York) had a consistent series of well-timed and clear wintertime satellite imagery for each of the four study years. Those counties therefore became the focus of the satellite groundcover analysis. Centre County, along with several other counties that had also participated in the "without carrot or stick" program, had no clear wintertime imagery available for one or more of the study years, due to cloudiness and snow cover. The lack of imagery for some counties points to the importance of satellite overpass repeat frequency in obtaining clear wintertime imagery; in some cases, satellite remote sensing remains limited by lack of good quality imagery.

For each of the four focus counties, a clear satellite image from the late winter of each year (table 3) was used to evaluate agricultural vegetative groundcover. However, within these images less than $100 \%$ of the landscape was sampled, due to occasional partial cloudiness and to Landsat 7 scan line errors (USGS 2014c). The missing pixels of information, ranging from $2.5 \%$ to $24.8 \%$ of the total area, were assumed to be randomly distributed with respect to cropping patterns in the landscape and were therefore judged to not affect the groundcover analysis.

In the winter of 2012 to 2013, no clear Landsat imagery was available for the study area, and a SPOT 5 satellite image was substituted. Although this imagery has a smaller pixel size $(10 \mathrm{~m}[33 \mathrm{ft}])$ than Landsat $(30 \mathrm{~m}$ [98 ft]), it also has a smaller footprint $(60 \times$
$60 \mathrm{~km}$ [37 × $37 \mathrm{mi}]$ ), which did not entirely cover each county (figure 1). The image therefore preferentially sampled portions of Berks (biased toward cropland), Lancaster (biased toward the northern portion of the county), and York (biased toward forest). The groundcover analysis for 2012 to 2013 therefore applies only to the sampled areas, unless it is assumed that cover cropping practices have a similar occurrence on corn land within the areas of each county that were sampled and not sampled by the imagery. The percentages of each county that were sampled by the imagery (the ratio of total sampled area to the total county area) are detailed in table 3. Overall, Lebanon County had the most consistent imaging of its land cover $(75 \%$ in February of 2012 due to cloudiness, $>97 \%$ in the other years).

The weather across the four fall to winter seasons was favorable to growth of cover crops. Although the imagery date varied somewhat by year (February 6 to April 6), the number of GDD between October 1 and the imagery acquisition date in each year was fairly consistent (713 to 895 GDD), with the warmest winter (2011 to 2012) balanced by an early imagery date (table 3 and figure 5a). All of the imagery, including the April 6 date, was acquired prior to springtime green-up as determined from MODIS eight-day greenness products (NASA 2014) and was representative of wintertime conditions (figure $5 b$ ).

Vegetative Groundcover Analysis. Within the sampled extent of each county, percentage land use identified as corn crops by the CDL remained fairly consistent over the four sampled years (table 4a), with the highest intensity of corn cropping in Lancaster County (23\% to $27 \%$ of total land area) followed by Lebanon (17\% to $21 \%$ of land area),York (12\% to $15 \%$ of land area) and Berks (9\% to $11 \%$ of land area). In 2012, the observed values for Berks and York counties (table 4a) were biased due to the location of the SPOT imagery within each county (figure 6), as described above. The CDL does not distinguish between corn harvest methods.

According to USDA NASS county statistics (table 4b), the percentage of COS ranged from $21 \%$ to $32 \%$ in Berks, $35 \%$ to $47 \%$ in Lancaster, $34 \%$ to $44 \%$ in Lebanon, and 9\% to $13 \%$ in York, and was fairly consistent over time with year-to-year variability linked to corn prices, forage availability, and a higher occurrence of silage harvest under dry condi- 


\section{Figure 4}

Box plots of (a) normalized difference tillage index (NDTI) and (b) normalized difference residue index (NDRI) by previous crop including corn harvested for grain (COG) and corn harvested for silage (COS), for windshield survey fields in Centre County, Pennsylvania (dark line = median, black point $=$ mean, white box $=25 \%$ quartiles, and whiskers $=$ range). Index values were derived using a November 14, 2010, Landsat 5 satellite image. The residue analysis was limited to 311 fields with minimal vegetative vegetative groundcover (NDVI $<0.25$ ).

(a)

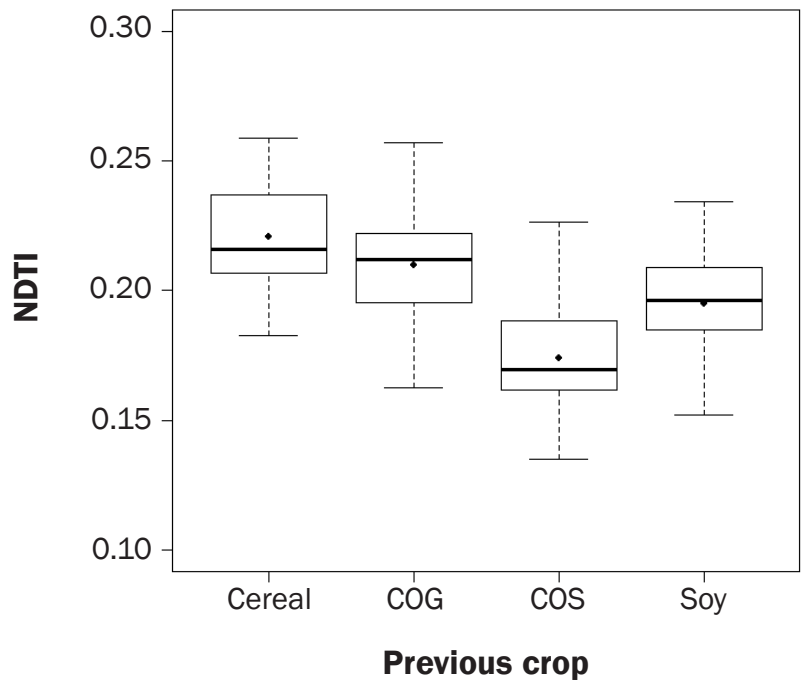

(b)

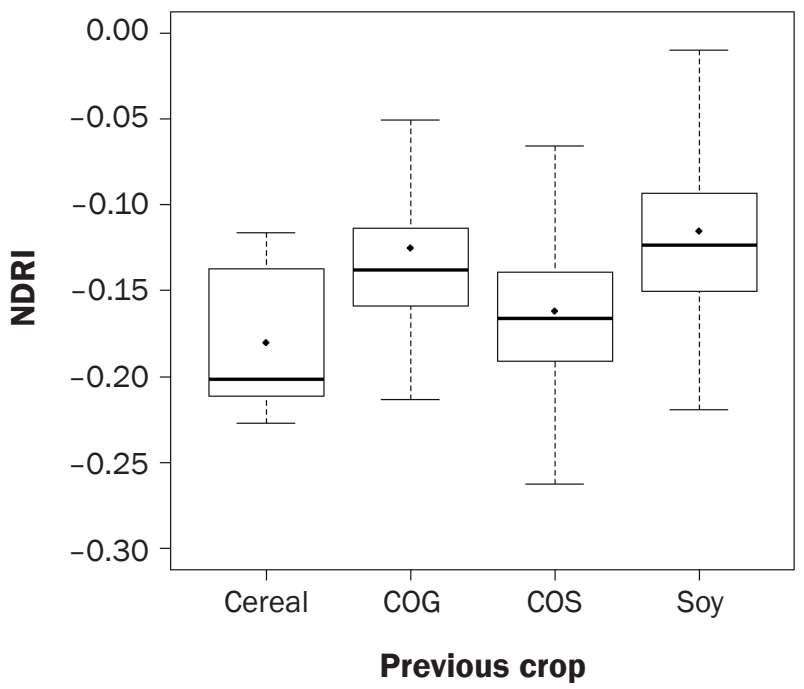

Table 3

Satellite imagery sources, dates, and coverage.

\begin{tabular}{|c|c|c|c|c|c|c|c|}
\hline Year & Image Date & $\mathrm{GDD}_{0}$ * & Sensor & \multicolumn{4}{|c|}{ Percentage of county sampled by imagery } \\
\hline 2009 to 2010 & March 20, 2010 & 876 & Landsat $7 \dagger$ & 75.2 & 85.8 & 96.8 & 91.8 \\
\hline 2011 to 2012 & February 6, 2012 & 865 & Landsat 7† & 80.5 & 87.6 & 96.5 & 91.0 \\
\hline 2012 to 2013 & April 6, 2013 & 895 & SPOT $5 \neq$ & 15.3 & 49.4 & 99.8 & 20.5 \\
\hline
\end{tabular}

* Number of growing degrees (GDD) accumulated between October 1 and the image date.

†Unsampled portions for Landsat 7 imagery resulted from cloud masking and scan line errors.

łUnsampled portions for System Probatoire d’ Observation de la Terre 5 imagery resulted from its smaller footprint.

tions. The overall occurrence of silage harvest was linked to predominance of dairy farming, with the lowest occurrence in York County, which also had the fewest dairy farms. Based on the windshield survey results (table 2), and confirmed by local knowledge, cover crops are more often used following silage harvest, rather than corn grain harvest, due to the earlier silage harvest dates, longer associated fall cover crop growing season, and the requirement that dairy farms spread wintertime manure on fields with $>25 \%$ groundcover.

The satellite remote sensing analysis of wintertime vegetation showed a steady four-year climb in the occurrence of winter groundcover following corn crops in each of the four focus counties (figure 7 and table 4c), with vegetative cover increasing from $36 \%$ to $67 \%$ of corn land in Berks, $53 \%$ to $75 \%$ in Lancaster, $42 \%$ to $65 \%$ in Lebanon, and $26 \%$ to $52 \%$ in York. In each county, the area of corn crops with minimal green wintertime vegetation decreased over time, while occurrence of nonminimal vegetative groundcover categories increased (figure 7). The observed slight increase in the percentage of corn fields with minimal groundcover from 2009/2010 to 2010/2011 might be linked to the somewhat smaller number of GDD in 2010/2011 (713) relative to the other 3 years $(876,865$, and 895) (figure 5). Photographs of vegetation levels associated with each of the vegetative groundcover classes are provided in figure $2 \mathrm{c}$. It should be noted that satellite remote sensing measures all green groundcover, including cover crops, fertilized winter cereal grains, and weeds.
Although vegetation indices such as the NDVI tend to be robust with respect to atmospheric interference, several researchers have documented the need to standardize to surface reflectance in interimage calibration (Brown et al. 2006; Guyot and Gu 1994; Masek et al. 2006; Song et al. 2001) due to possible effects of atmosphere on the dynamic range of NDVI measurements. To test whether the observed four-year trend of increasing groundcover could possibly be explained by an unlucky trend in atmospheric interference across the time period, top of atmosphere (TOA) reflectance values for pixels falling within cropland were subtracted from their corresponding surface reflectance (SR) values for each of the three Landsat images, using cloud-masked TOA 


\section{Figure 5}

(a) Accumulated growing degrees (GDD) after October 1 for each of four study years (solid lines), with biweekly precipitation (inverted bars), and accumulated GDD totals associated with satellite imagery dates (vertical dashed lines), using 2009 to 2013 weather data from the Lancaster Airport, Lancaster, Pennsylvania, and (b) MODIS normalized difference vegetation index (NDVI) eight day greenness index. Black boxes indicate imagery acquisition dates.

(a)
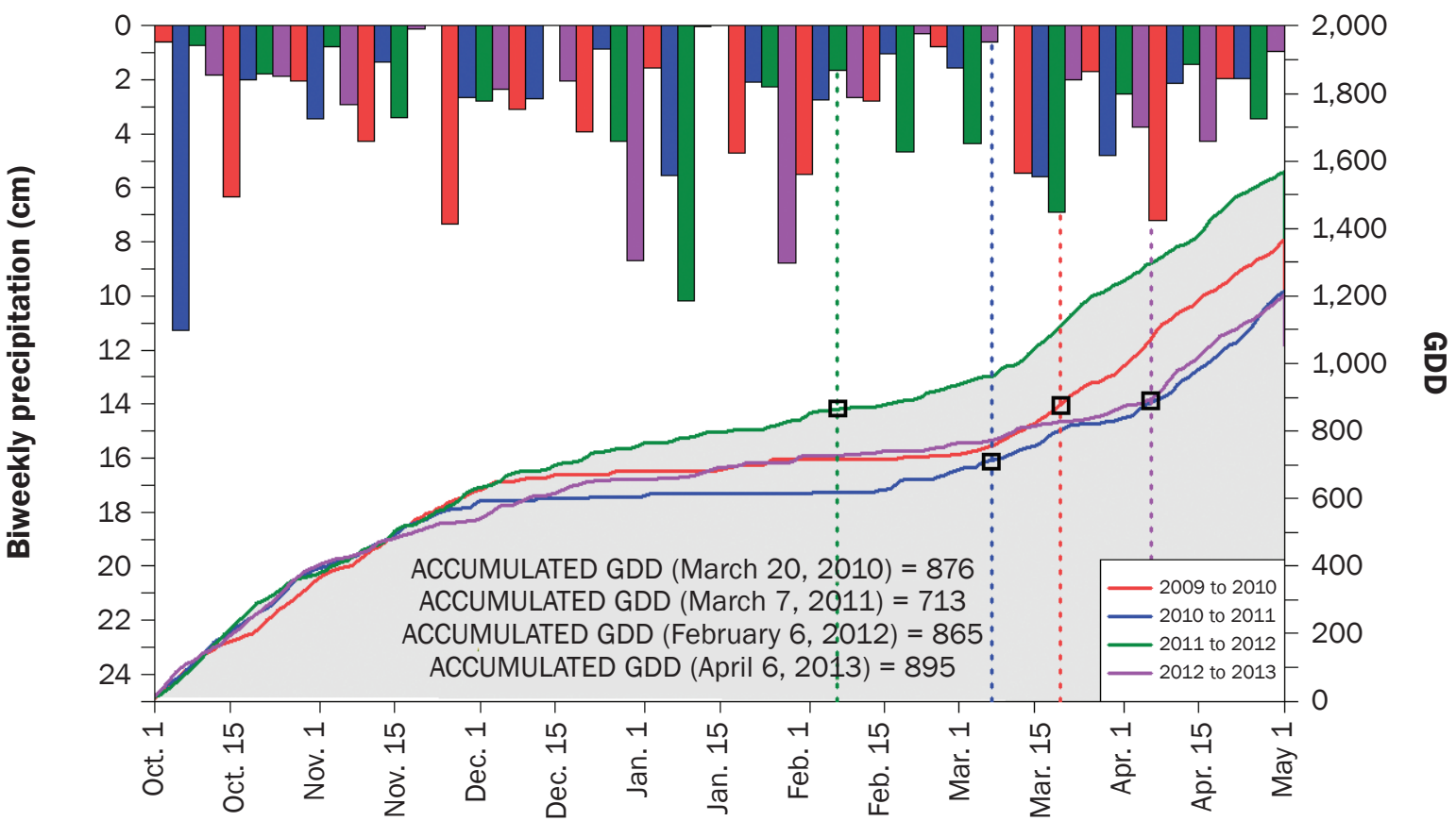

Date

(b)

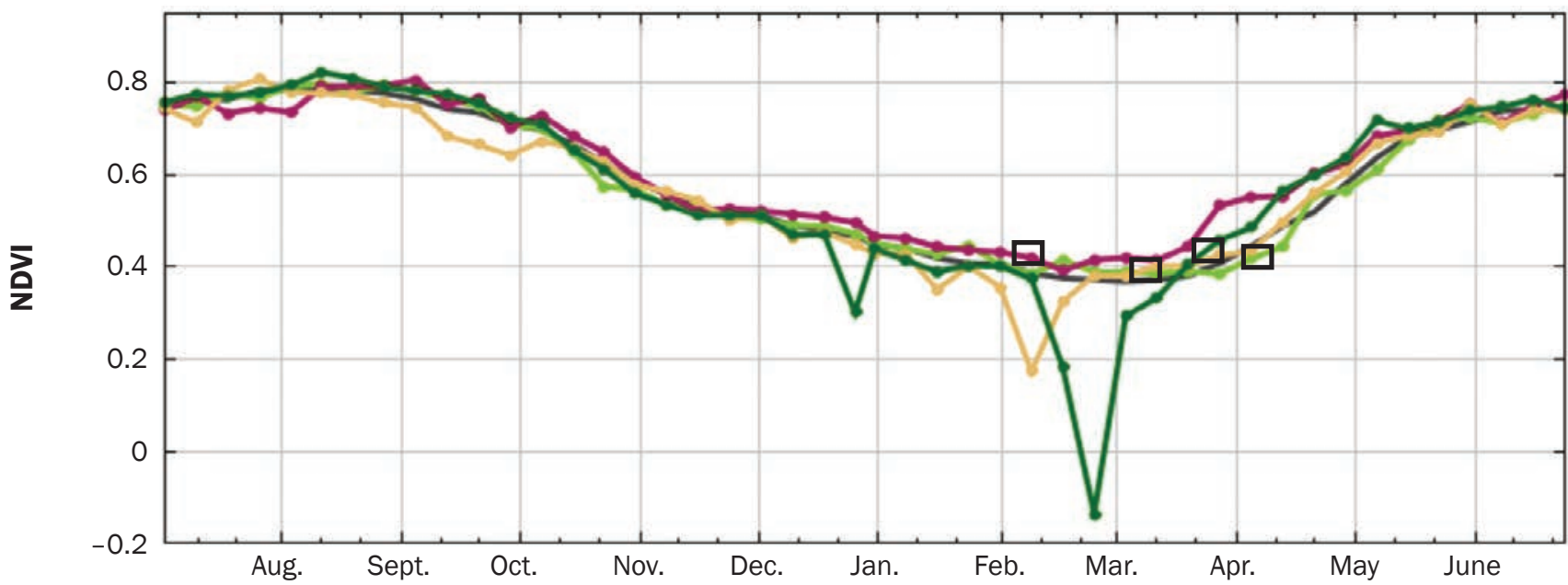

Legend

Date 


\section{Table 4}

Occurrence of corn crops and wintertime vegetation in four Pennsylvania counties.

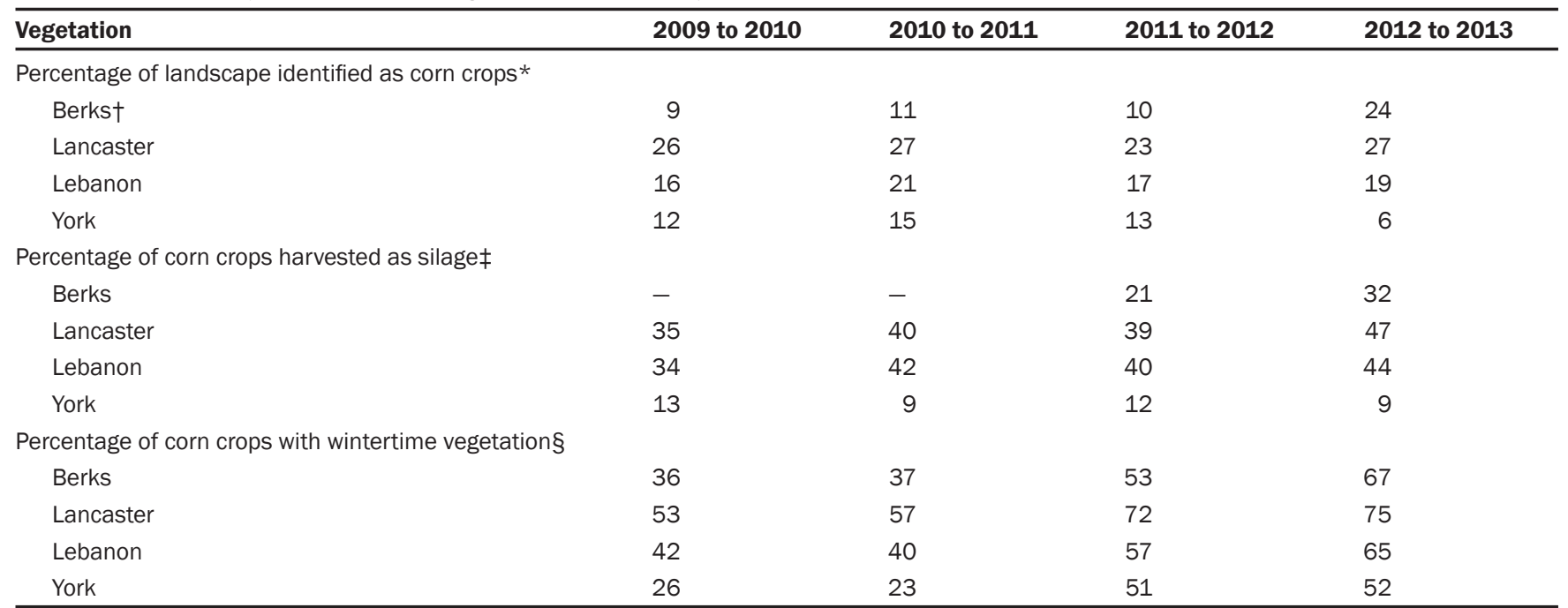

*Based on annual USDA National Agricultural Statistics Service Cropland Data Layer, Underscored values in 2012 were skewed by the location of the System Probatoire d' Observation de la Terre satellite footprint.

†Total area of counties is 224,000; 254,350; 94,000; and 236,200 ha for Bates, Lancaster, Lebanon, and York, respectively.

¥From annual USDA National Agricultural Statistics Service county crop harvest data. Dashes indicate missing data.

$\S$ Scored as nonminimal (low, medium, or high) vegetation in satellite analysis of areas identified as corn in the annual Cropland Data Layer.

\section{Figure 6}

Cropland Data Layer (2010) with county boundaries (purple), System Probatoire d' Observation de la Terre 5 SPOT satellite footprint (red), and windshield survey field locations (blue). Yellow pixels indicate corn crops in 2010.

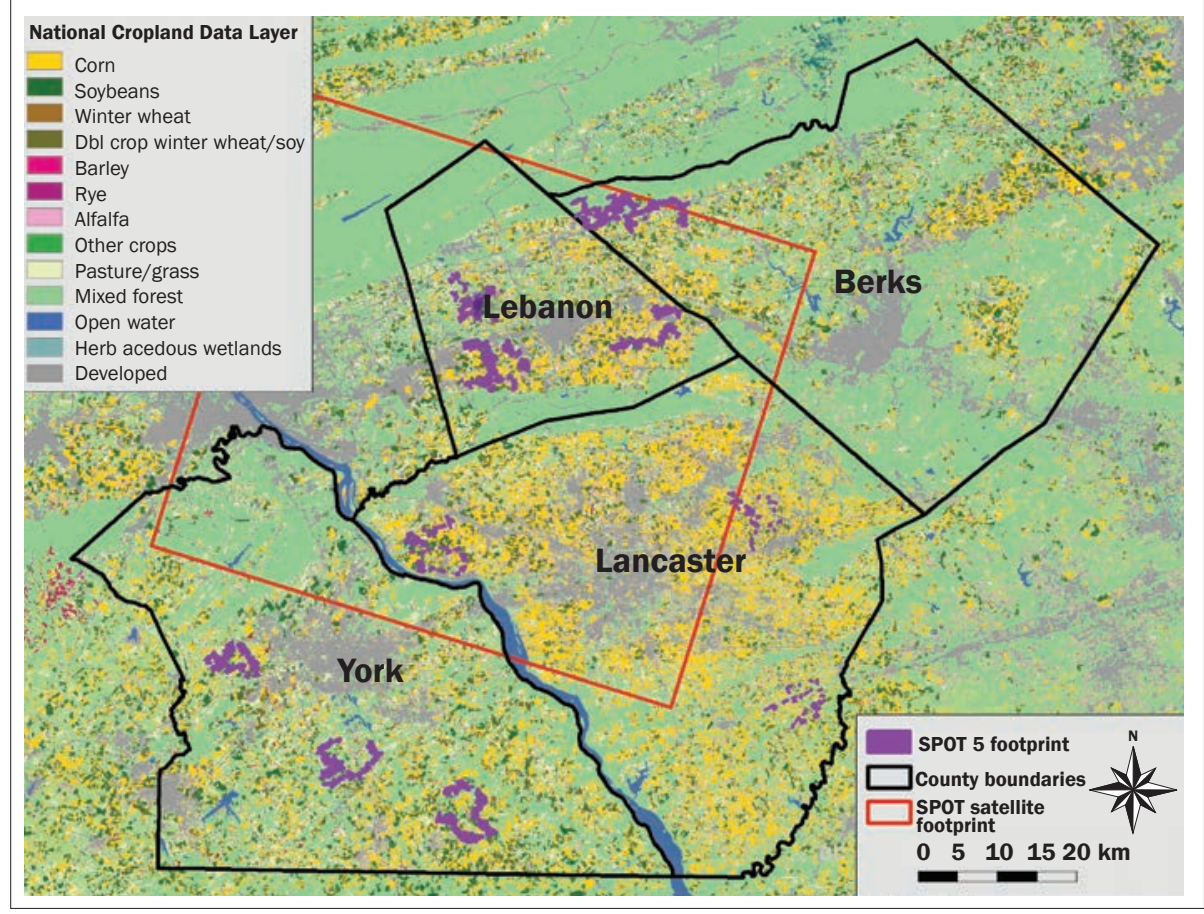

and SR products provided by the USGS Earth Resources Observation and Science Center. When histograms of the SR-TOA differences were compared among dates, it was evident that atmospheric effects on NDVI were minimal for the dates of analysis, with mean differences of 0.027 (March 20, 2010), 0.031 (March 7, 2011) and 0.037 (February 6, 2012) and standard deviations of $0.015,0.013$ and 0.017 , respectively. Additionally, Aeronet data (Holben 1998) were used to calculate atmospheric optical thickness at the times of image acquisition, and all four dates were judged to be similar in having a clear atmosphere (visibility of $64,222,145$, and $74 \mathrm{~km} \mathrm{[40,138,} \mathrm{90,} \mathrm{and} 46$ $\mathrm{mi}$ for the four image dates). Overall, atmospheric effects on NDVI were judged to be minimal for the four specific cloud-free satellite acquisition dates used for this project, and the threshold NDVI values used in the groundcover analysis were therefore judged to be stable, indicating that the observed trends were not attributable to differences in atmospheric effects.

Additionally, to investigate possible differences in NDVI sensitivity and threshold values between SPOT and Landsat TOA imagery, a dataset was acquired on November 18, 2011, over the USDA ARS Beltsville Agricultural Research Center (Beltsville, Maryland), where imagery from 


\section{Figure 7}

Late-winter vegetative groundcover following corn crops in (a) Berks, (b) Lancaster, (c) Lebanon, and (d) York counties, Pennsylvania, determined from satellite remote sensing.

(a)

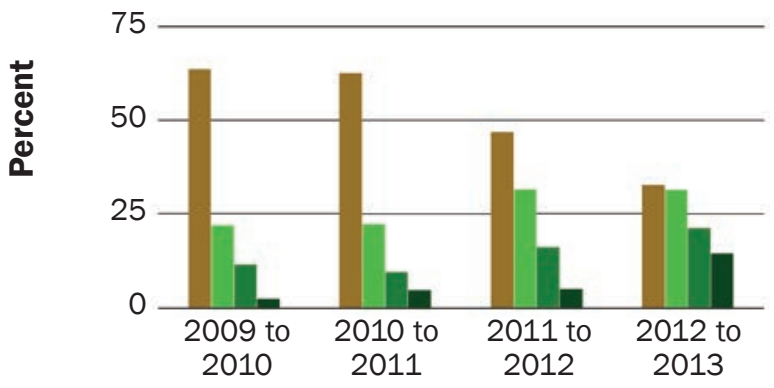

(c)

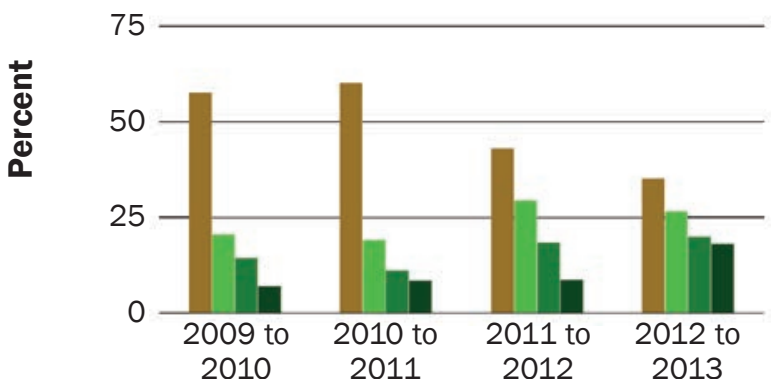

(b) 100

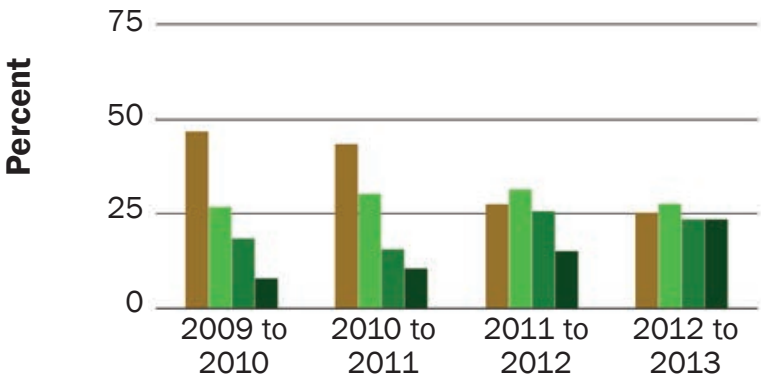

(d) 100

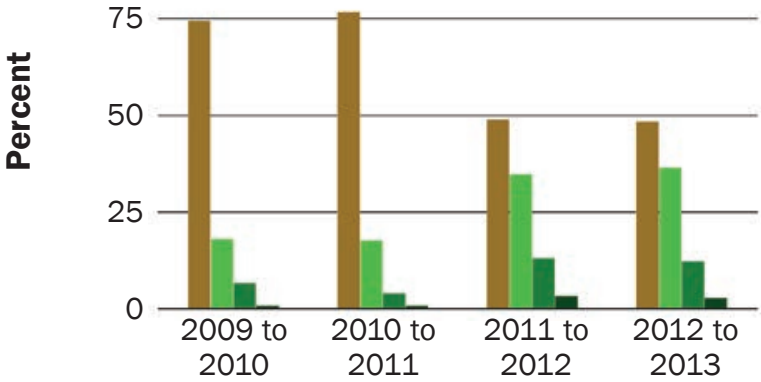

\section{Legend Vegetation class \\ Minimal Low Medium High}

both satellites was collected within the same hour of the day and NDVI values were compared for 50 field locations. Results showed a close relationship between the NDVI values derived from the two sensors $\left(r^{2}=0.98\right)$ with SPOT NDVI $=0.015+0.88$ Landsat NDVI. This calculation results in a SPOT NDVI value of 0.28 equivalent to a Landsat NDVI value of 0.30 , implying that the cutoff threshold for minimal vegetative groundcover $(\mathrm{NDVI}=0.30)$ is relatively consistent between the satellites.

From the satellite vegetation analysis, it was apparent that the occurrence of wintertime vegetative groundcover on agricultural fields previously cropped to corn increased by $29 \%$ in Berks County, 22\% in Lancaster, $23 \%$ in Lebanon, and 26\% in York between 2009 and 2012, likely resulting from increased farmer adoption of winter cover crops. In addition to corn crops, similar analytical results were calculated describing winter groundcover following each of the top 10 summertime land use categories from the CDL (data available at https://www. sciencebase.gov/catalog/folder/5513353ce4 b02e76d75c0993).

\section{Summary and Conclusions}

Satellite imagery was used to characterize levels of wintertime green vegetative groundcover on agricultural fields in four counties in southeastern Pennsylvania, for four consecutive years. Windshield survey data were used to document groundcover occurrence following corn harvested for grain (COG) versus corn harvested for silage (COS) and to confirm calibration of satellite imagery interpretation. Late-winter satellite images were acquired using the Landsat 7 and SPOT 4 satellite platforms, and previous-summer agricultural crop types were mapped using the USDA NASS CDL. These datasets were then combined to determine four-year trends in wintertime vegetative groundcover in four counties (Berks, Lancaster, Lebanon, and York).

Results of satellite vegetation analysis demonstrated a consistent trend toward increased wintertime vegetative groundcover following corn crops, likely associated with increased adoption of cover crops. Between 2010 and 2013 the occurrence of wintertime vegetation on agricultural fields increased from $36 \%$ to $67 \%$ of corn fields in Berks County, from 53\% to $75 \%$ in Lancaster County, from $42 \%$ to $65 \%$ in Lebanon County, and from $26 \%$ to $52 \%$ in York County. Apparently, efforts to promote cover crop use in the Chesapeake Bay Watershed have coincided with a rapid increase in the occurrence of wintertime vegetation following corn harvest in south- 
eastern Pennsylvania. However, despite these increases, between $25 \%$ and $48 \%$ of corn fields remained without living vegetation over the wintertime, indicating further opportunity for cover crop adoption.

For fields included in the windshield survey, wintertime greenness was higher for fields following silage harvest than for fields following corn grain harvest, as indicated by both the survey biomass data and the associated satellite NDVI, demonstrating that cover crops are more frequently used following silage, most likely due to the longer fall growing season made possible by the earlier corn harvest dates. When windshield survey satellite analysis was limited to low-vegetation fields, COG displayed higher NDTI and NRDI values than COS and soy crops, likely due to the greater amount of crop residue retained following grain harvest. The observed differences could possibly be exploited on an operational basis to distinguish between COG and COS, as long as imagery was acquired after corn harvest and prior to fall tillage and analysis was limited to fields with minimal vegetation.

Results of this study show that remote sensing techniques can be used successfully to map winter groundcover on agricultural fields, despite some confounding factors including mixed pixels resulting from strip cropping and missing data due to partial cloudiness and Landsat 7 scan line errors. Although remote sensing remains limited by satellite return frequency, pixel size, spectral resolution, and the availability of cloud free imagery, future deployment of satellites will improve the capacity for providing timely, accurate, field-specific measurements of agricultural vegetation at the landscape scale.

\section{Acknowledgements}

Thank you to the county extension agents in Pennsylvania who took time to collect the windshield survey data, to University of Maryland geography graduate student Mouhamad Diabate for technical support, and to Roosevelt High School Science and Technology student interns Tolulope Adetayo and Collette Harding for digitizing the windshield survey data. We are grateful to Craig Daughtry, research agronomist with the USDA ARS Hydrology and Remote Sensing Laboratory, and to an anonymous reviewer for providing helpful input for manuscript revisions. This project was supported by the US Geological Survey Climate and Land Use Program, the USDA Choptank River Conservation Effects Assessment Project, and by a Chesapeake Bay Innovative Nutrient and Sediment Reduction grant administered by the National
Fish and Wildlife Foundation. Any use of trade, firm, or product names is for descriptive purposes only and does not imply endorsement by the US Government. The data supporting this manuscript are available at https://www. sciencebase.gov/catalog/folder/5513353ce4b02e76d75c0993.

\section{References}

Aase, J.K., and D.L. Tanaka. 1991. Reflectances from four wheat residue cover densities as influenced by three soil backgrounds. Agronomy Journal 83:753-757.

Bannaria, A., D. Morina, F. Bonna, and A.R. Hueteb. 1995. A review of vegetation indices. Remote Sensing Reviews 13:95-120.

Boryan, C., Z. Yang, R. Mueller, and M. Craig. 2011. Monitoring US agriculture: The US Department of Agriculture, National Agricultural Statistics Service, cropland data layer program. Geocarto International 26:341-358.

Brown, M.E., J.E. Pinzon, K. Didan, J.T. Morisette, and C.J. Tucker. 2006. Evaluation of the consistency of long-term NDVI time series derived from AVHRR, SPOT-vegetation, SeaWiFS, MODIS, and Landsat ETM+ sensors. IEEE Transactions on Geoscience and Remote Sensing 44(7):1787-1793.

CBP (Chesapeake Bay Program). 2014. Cover crops: One key to reducing nutrients to the bay. Annapolis, MD: Chesapeake Bay Program. http: / / www.chesapeakebay.net/blog/post/ cover_crops_one_key_to_reducing_nutrients_to_bay.

Dabney, S.A., J.A. Delgado, and D.W. Reeves. 2001. Using winter cover crops to improve soil and water quality. Communications in Soil Science and Plant Analysis 32(7-8):1221-1250.

Daughtry, C.S.T. 2001. Discriminating crop residues from soil by shortwave infrared reflectance. Agronomy Journal 93:125-131.

Daughtry, C.S.T., P.C. Doraiswamy, E.R. Hunt Jr., A.J. Stern, J.E. McMurtrey III, and J.H. Prueger. 2006. Remote sensing of crop residue cover and soil tillage intensity. Soil and Tillage Research 91:101-106.

Daughtry, C.S.T., G. Serbin, J.B. Reeves III, P.C. Doraiswamy, and E.R. Hunt Jr. 2010. Spectral reflectance of wheat residue during decomposition and remotely sensed estimates of residue cover. Remote Sensing 2:416-431.

De Baets, S., J. Poesen, J. Meermans, and L. Serlet. 2011. Cover crops and their erosion-reducing effects during concentrated flow erosion. Catena 85:237-244.

DEP (Department of Environmental Protection). 2011 Land Application of Manure: A Supplement to Manure Management for Environmental Protection. Manure Management Plan Guidance 361-0300-02. Harrisburg, PA Pennsylvania Department of Environmental Protection.

Duiker, S.W. 2014. Establishment and termination dates affect fall-established cover crops. Agronomy Journal 106:670-678

Gausman, H.W., R.W. Leamer, J.R. Noriega, R.R. Rodriguez, and C.L. Weigand. 1977. Field-measured spectroradiometric reflectances of disked and nondisked soil with and without wheat straw. Soil Science Society of America Journal 41:793-796.

Gelder, B.K., A.L. Kaleita, and R.M. Cruse. 2009. Estimating mean field residue cover on Midwestern soils using satellite imagery. Agronomy 101(3):635-643.

Guyot, G., and X-F Gu. 1994. Effect of radiometric corrections on NDVI determined from SPOT-HRV and Landsat-TM data. Remote Sensing of Environment 49:169-180.

Hesterman, O.B., T.S. Griffin, P.T. Williams, G.H. Harris, and D.R. Christenson. 1992. Forage legume-small grain intercrops: Nitrogen production and response of subsequent corn. Journal of Production Agriculture $5: 340-348$.

Hively, W.D., O. Devereux, and P. Claggett. 2013. Integrating Federal and State Data Records to Report Progress in Establishing Agricultural Conservation Practices on Chesapeake Bay Farms. US Geological Survey Open File Report 2013-1287. http://pubs.usgs. gov/of/2013/1287/.

Hively, W.D., G.W. McCarty, and J. Keppler. 2009a. Federalstate partnership yields success in remote sensing analysis of conservation practice effectiveness: Results from the Choptank River Conservation Effects Assessment Project. Journal of Soil and Water Conservation 64(5):154A, doi:10.2489/jswc.64.5.154A. http://www.jswconline. org/content/64/5/154A.full.pdf.

Hively, W.D., M. Lang, G.W. McCarty, J. Keppler, A. Sadeghi, and L. McConnell. 2009b. Using satellite remote sensing to estimate winter cover crop nutrient uptake efficiency.Journal of Soil and Water Conservation 64(5):303-313, doi:10.2489/jswc.64.5.303. http:// www.jswconline.org/content/64/5/303.full.pdf.

Holben, B.N., T.F. Eck, I. Slutsker, D. Tanré, J.P. Buis, A. Setzer, E. Vermote, J.A. Reagan, Y.J. Kaufman, T. Nakajima, F. Lavenu, I. Jankowiak, and A. Smirnov. 1998. AERONET - A federated instrument network and data archive for aerosol characterization. Remote Sensing of Environment 66:1-16.

Hunt, E.R. Jr., W.D. Hively, G.W. McCarty, C.S.T. Daughtry, P.J. Forrestal, R.J. Kratochvil, J.L. Carr, N.F. Allen, J.R. Fox-Rabinovitz, and CD. Miller. 2011. NIR-green-blue high-resolution digital images for assessment of winter cover crop biomass. GIScience and Remote Sensing 48(1):86-98.

Magdoff, F., and H.Van Es. 2009. Building Soils for Better Crops. Handbook Series Book 4. Beltsville, MD: Sustainable Agriculture Network.

Magdoff, F., and H. Van Es. 2009. Building Soils for Better Crops: Sustainable Soil Management. Waldorf, MD: Sustainable Agriculture Research and Education.

Maryland Department of Agriculture (MDA). 2014. Maryland's 2014-15 Cover Crop Sign Up. Annapolis, MD: Maryland Department of Agriculture. http://mda. maryland.gov/resource_conservation/Pages/cover_ crop.aspx. 
Masek, J.G., E.F. Vermote, N.E. Saleous, R. Wolfe, F.G. Hall, K.F. Huemmrich, F. Gao, J. Kutler, and T-K Lim. 2006. A Landsat surface reflectance dataset for North America: 1990-2000. IEEE Geoscience and Remote Sensing Letters 3(1):68-72.

Miller P., W. Lanier, and S. Brandt. 2001. Using growing degree days to predict plant stages. Montana State University Extension Service, MT200103 AG. http:// www.ipm.montana.edu/Training/PMT../2006/ mt200103.pdf.

Moges, S.M., W.R. Raun, R.W. Mullen, K.W. Freeman, G.V. Johnson, and J.B. Solie. 2004. Evaluation of green, red, and near infrared bands for predicting winter wheat biomass, nitrogen uptake, and final grain yield. Journal of Plant Nutrition 27(8):1431-1441.

Nagler, P.L., C.S.T. Daughtry, and S.N. Goward. 2000. Plant litter and soil reflectance. Remote Sensing of Environment 71:207-215.

NASA (National Aeronautics and Space Administration). 2014. MODIS Land, Vegetation Indicies. http:// modis-land.gsfc.nasa.gov/vi.html.

Prabhakara, K., W.D. Hively, and G.W. McCarty. 2015. Evaluating the relationship between biomass, percent groundcover and remote sensing indices across six winter cover crop fields in Maryland, United States. International Journal of Applied Earth Observation and Geoinformation 39:88-102.

SANET (Sustainable Agriculture Network). 2007. Managing Cover Crops Profitably, 3rd edition. Handbook Series Book 9. Beltsville, MD: Sustainable Agriculture Network.

Sarrantonio, M., and E. Gallandt. 2003. The role of cover crops in North American cropping systems. Journal of Crop Production 8(1-2):53-74. http://www. tandfonline.com/doi/pdf/10.1300/J144v08n01_04.

Serbin, G., C.S.T. Daughtry, E.R. Hunt, Jr., and D.J. Brown. 2009a. Effect of soil spectral properties on remote sensing of crop residue cover. Soil Science Society of America Journal 73:1545-1558.

Serbin, G., E.R. Hunt, C.S.T. Daughtry, G.W. McCarty, and P.C. Doraiswamy. 2009b. An improved ASTER index for remote sensing of crop residue. Remote Sensing 2009(1):971-991.

Singer, J.W., R.W. Malone, D.B. Jaynes, and L. Ma. 2011. Cover crop effects on nitrogen load in tile drainage from Walnut Creek Iowa using root zone water quality (RZWQ) model. Agricultural Water Management 98:1622-1628.

Song, C., C.E. Woodcock, K.C. Seto, M.P. Lenney, and S.A. Macomber. 2001. Classification and change detection using Landsat TM data: When and how to correct atmospheric effects? Remote Sensing of Environment 75:230-244.

Staver, K., and R. Brinsfield. 1998. Using cereal grain winter cover crops to reduce groundwater nitrate contamination in the mid-Atlantic coastal plain. Journal of Soil and Water Conservation 53(30):230-240.
Teasdale, J.R., L.O. Brandsaeter, A. Calegari, and F. Skora Neto. 2007. Cover crops and weed management. In Non-Chemical Weed Management Principles, Concepts, and Technology, eds. M.K. Upadhyaya and R.E. Blackshaw. Cambridge, MA: CAB International.

Thenkabail, P.S., R.B. Smith, and E. De Pauw. 2000. Hyperspectral vegetation indices and their relationships with agricultural crop characteristics. Remote Sensing of Environment 71(2):158-182.

USDA FSA (Farm Service Agency). 2014. National Agriculture Imagery Program (NAIP). http://www.fsa. usda.gov/programs-and-services/aerial-photography/ imagery-programs/naip-imagery/index.

USGS (US Geological Survey). 2014a. Earth Explorer Homepage. http://earthexplorer.usgs.gov/.

USGS. 2014b. Earth Resources Observation and Science (EROS) Center Homepage. http://eros.usgs.gov/.

USGS. 2014c. Landsat Missions, SLC-off Products: Background. http://landsat.usgs.gov/products_slcoffbackground.php.

Woodcock, C.E. 2008. Free access to Landsat imagery. Science 320(5879):1011.

Zhang, Q., D.C. Brady, and W.P. Ball. 2013. Long-term seasonal trends of nitrogen, phosphorus, and suspended sediment load from the non-tidal Susquehanna River Basin to Chesapeake Bay. Science of the Total Environment 452/453:208-221. 